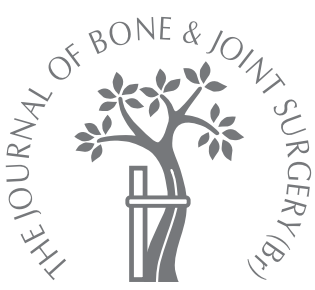

I. Starks, S. Roberts, S. H. White

From Robert Jones and Agnes Hunt Orthopaedic Hospital, Gobowen, Shropshire, England

\title{
The Avon patellofemoral joint replacement
}

\author{
INDEPENDENT ASSESSMENT OF EARLY FUNCTIONAL OUTCOMES
}

We present a prospective review of the two-year functional outcome of 37 Avon patellofemoral joint replacements carried out in 29 patients with a mean age of 66 years (30 to 82 ) between October 2002 and March 2007. No patients were lost to follow-up. This is the first independent assessment of this prosthesis using both subjective and objective analysis of outcome. At two years the median Oxford knee score was 39 (interquartile range 32 to 44), the median American Knee Society objective score was 95 (interquartile range 90 to 100), the median American Knee Society functional score was 85 (interquartile range 60 to 100), and the median Melbourne Knee score was 28 (interquartile range 21 to 30). Two patients underwent further surgery. Only one patient reported an unsatisfactory outcome.

We conclude that the promising early results observed by the designing centre are reproducible and provide further support for the role of patellofemoral joint replacement.

It is reported that between $3 \%$ and $5 \%$ of patients with isolated patellofemoral arthritis undergo total knee replacement (TKR) primarily for patellofemoral disease. ${ }^{1,2}$ Although the pathophysiology of the disease is multifactorial, it is believed that the final common pathway is the result of abnormal load across the patellofemoral joint. ${ }^{3}$ Causes include malalignment, dysplasia, instability, trauma, inflammatory arthritis and idiopathic osteoarthritis. ${ }^{4}$

A number of operative strategies have been tried in patients with isolated patellofemoral joint osteoarthritis in whom conservative measures have failed. These include arthroscopic treatment, comprising chondroplasty, microfracture and lateral release, realignment procedures either of the soft tissue or by osteotomy, attempts at biological restoration of the articular surface by mosaicplasty, or autologous chondrocyte implantation (ACI), facetectomy or patellectomy. The results of these procedures have been variable. ${ }^{5}$ Although surgeons may attempt these procedures, the final solution is likely to be a TKR. Many surgeons feel such treatment is excessive as it entails excising a normal tibiofemoral articulation.

Patellofemoral joint resurfacing originally gained interest in the late $1970 \mathrm{~s},{ }^{6}$ with publication of the results of the first generation of patellofemoral joint replacements. ${ }^{7}$ However, the high failure rates reported with some of the early designs, such as the Lubinus device, ${ }^{8}$ have resulted in many knee surgeons preferring the proven track record of TKR for isolated patellofemoral joint arthritis. A better understanding of patellofemoral kinematics has seen the development of a number of secondgeneration prostheses. The Avon (Stryker Howmedica Osteonics, Allendale, New Jersey) design was developed from the Kinemax plus TKR (Stryker Howmedica Osteonics) which had a low rate of patellofemoral complications. The early- to mid-term results of this prosthesis from the originating centre have been promising. ${ }^{9}$ This is the first independent assessment of this prosthesis using both subjective and objective analysis of outcome.

\section{Patients and Methods}

A prospective series of 37 consecutive Avon patellofemoral joint replacements were performed on 29 patients between October 2002 and March 2007. Eight patients underwent bilateral procedures, four of which were carried out at the same time. There were eight men and 21 women, with a mean age of 66 years (30 to 82 ). The indication for surgery in all but one case was isolated patellofemoral joint arthritis. One patient had had failed ACI for an osteochondral defect of the patella. Diagnosis was based on a combination of clinical, radiological and, where available, arthroscopic findings. Each patient had a minimum of a weight-bearing anteroposterior and a lateral radiograph of their knee. In total, nine patients had previously undergone surgical treatment (Table I). 
Table I. Previous surgery in the 37 knees

\begin{tabular}{ll}
\hline Procedure & Number of knees \\
\hline Arthroscopy & 6 \\
Lateral release & 1 \\
Fixation of patellar fracture & 1 \\
Autologous chondrocyte implantation & 1 \\
\hline
\end{tabular}

All operations were undertaken by, or under the supervision of, the senior author (SHW) using the technique described by the designing surgeon. ${ }^{10}$ Patients were followed up at six weeks and two years. Clinical review was carried out by the operating surgeon and a physiotherapist (SR). Radiographs were reviewed for the development of and/or the progression of tibiofemoral arthritis using the Ahlback grading. ${ }^{11}$ Functional outcome was assessed at two years using the Oxford knee score (OKS), ${ }^{12}$ the American Knee Society (AKS) objective and functional scores ${ }^{13}$ and the Melbourne patellar score. ${ }^{14}$ Patient satisfaction with the outcome of the surgery was also documented. All results were entered into the senior author's knee database.

\section{Results}

No patient was lost to follow-up, leaving 37 knees available for assessment at two years post-operatively. At this stage the median OKS was 39 (interquartile range (IQR) 32 to 44). The median AKS objective score was 95 (IQR 90 to 100). Using this score, 32 knees $(86 \%)$ were considered to have an excellent result (score $\geq 80$ ). The median AKS functional score was 85 (IQR 60 to 100). The median Melbourne score was 28 (IQR 21 to 30). At the two-year review all but one patient was satisfied with the results of surgery. The results are compared with the current literature in Table II.

One patient had developed asymptomatic radiological signs of minor medial compartment osteoarthritis at two years (Ahlback grade 1) and one patient was dissatisfied with the results of surgery despite normal clinical and radiological findings. Her post-operative scores were 16 for the OKS, 52 for the AKS (objective), 30 for the AKS (functional), and 17 for the Melbourne score.

There were complications in two patients. One did not undergo patellar resurfacing at the time of initial surgery because the eroded patella was very thin, and at that time the manufacturer's recommendations were not to resurface if the residual bone was $<12 \mathrm{~mm}$ thick. She subsequently underwent resurfacing at one year because of ongoing symptoms after advice from the originating surgeon. Following this she made excellent progress, with a two-year OKS of 47 and a Melbourne patellar score of 30. The second patient had a patellar fracture with separation of the distal patellar fragment from the button 14 months postoperatively. She underwent uncomplicated removal of the distal patellar fragment and revision of the patellar button. Her OKS was 44 and Melbourne patellar score 28 at the two-year review.

\section{Discussion}

This study shows that good results can be achieved in the short term with the Avon patellofemoral joint replacement. The high AKS scores we observed are supported by the high post-operative OKS, as well as the Melbourne patellar scores. All but one patient expressed satisfaction with the outcome of their surgery.

Although the designing surgeons have recently published their five-year results, very little has been published independently about this prosthesis. ${ }^{7,15}$ Our series is the largest to date from an independent centre and the only one with post-operative functional scores. Our observations are strengthened by the fact that no patients were lost to follow-up, and any complications have been presented. This series includes our introductory experience with this new prosthesis. The main weakness of our study is a lack of pre-operative scores in half our patients.

Our results compare favourably with those published by the designing centre ${ }^{8}$ as well as those published for TKR in patients with isolated patellofemoral arthritis (Table II). ${ }^{1,2,16}$ Our post-operative scores are also comparable to the senior author's previously published outcomes for TKR and medial unicompartmental knee replacement. ${ }^{17,18}$

The concept of patellofemoral joint replacement is attractive for those patients with isolated patellofemoral arthritis in whom other treatments have failed. It has several potential advantages over TKR, owing mainly to the preservation of the normal tibiofemoral articulation and the cruciate ligaments. This results in a kinematic profile that is closer to normal than that following TKR, in which the anterior cruciate ligament has been sacrificed. ${ }^{3,19}$ This should be taken in conjunction with the fact that patellofemoral joint replacement is a less invasive procedure, and may result in a reduced length of stay and faster rehabilitation. A further advantage of patellofemoral joint replacement lies in its potential for subsequent conversion to a TKR in the event of disease progression. There is evidence that the results of TKR after revision of a failed patellofemoral arthroplasty are not compromised. ${ }^{20}$ This is of particular importance as isolated patellofemoral arthritis tends to present in younger patients, in whom the revision rates for TKR are known to be higher. ${ }^{3}$

In the past, concerns were raised over the high rates of revision with the first generation of patellofemoral joint replacements. This has resulted in several implants being either abandoned or redesigned, ${ }^{8}$ and favours the use of TKR in this group of patients. However, the early to midterm results from originating centres of the second-generation implants, such as the Avon patellofemoral replacement and the Low Contact Stress patellofemoral replacement from DePuy, are promising. ${ }^{9,21}$

One concern about patellofemoral joint replacement is the potential for progression of osteoarthritis in the remaining compartments of the knee. Nicol et al, ${ }^{22}$ using the Avon prosthesis, reported a revision rate due to disease progression of $12 \%$ in their patients after a mean of 7.1 years. 
Table II. A comparison of our results with those previously published for the Avon patellofemoral arthroplasty and total knee replacement for isolated patellofemoral arthritis

\begin{tabular}{|c|c|c|c|c|c|c|c|c|c|}
\hline Author/s & Implant & $\begin{array}{l}\text { Number } \\
\text { (knees/ } \\
\text { patients) }\end{array}$ & $\begin{array}{l}\text { Mean age } \\
\text { (yrs) }\end{array}$ & $\begin{array}{l}\text { Mean } \\
\text { follow-up } \\
\text { (yrs) }\end{array}$ & OKS & $\begin{array}{l}\text { AKS }^{\dagger}- \\
\text { objective }\end{array}$ & $\begin{array}{l}\text { AKS- } \\
\text { functional }\end{array}$ & $\begin{array}{l}\text { Melbourne } \\
\text { score }\end{array}$ & Success rate \\
\hline \multirow[t]{2}{*}{ Ackroyd et al ${ }^{9}$} & Avon & $109 / 85$ & 68 & 2 & 37 & - & - & - & $\begin{array}{l}80 \% \text { at } 5 \text { yrs (Bristol } \\
\text { pain score }>20 \text { ) }\end{array}$ \\
\hline & & & & 5 & 39 & & & 25 & \\
\hline Leadbetter et $\mathrm{al}^{7}$ & Avon & $30 / 25$ & 48 & 2 & - & - & - & - & 83\% (own criteria) \\
\hline Mohammed et al ${ }^{15}$ & $\begin{array}{l}\text { Avon Lubinus } \\
\text { Femoro Patella } \\
\text { Vialla }\end{array}$ & $\begin{array}{l}101 / 91(25 \\
\text { Avons) }\end{array}$ & 57 & 4 & - & - & - & - & $\begin{array}{l}72 \% \text { (not requiring } \\
\text { further surgery) }\end{array}$ \\
\hline Mont et al ${ }^{6}$ & $\begin{array}{l}\text { Total knee replace- } \\
\text { ment ( } 3 \text { types) }\end{array}$ & $30 / 27$ & Not stated & 6.7 & - & 93 & 86 & - & $\begin{array}{l}97 \% \text { (AKS objective) } \\
>80)\end{array}$ \\
\hline Dalury ${ }^{1}$ & $\begin{array}{l}\text { Total knee replace- } \\
\text { ment (pressfit } \\
\text { condylar) }\end{array}$ & $33 / 25$ & 70 & 5.2 & - & 96 & - & - & $\begin{array}{l}\text { All patients had } \\
\text { good to excellent } \\
\text { results }\end{array}$ \\
\hline Our results & Avon & $37 / 29$ & 66 & 2 & 39 & 95 & 85 & 28 & $\begin{array}{l}86 \% \text { (AKS objective } \\
>80 \text { ) }\end{array}$ \\
\hline
\end{tabular}

* OKS, Oxford knee score

† AKS, American Knee Society score

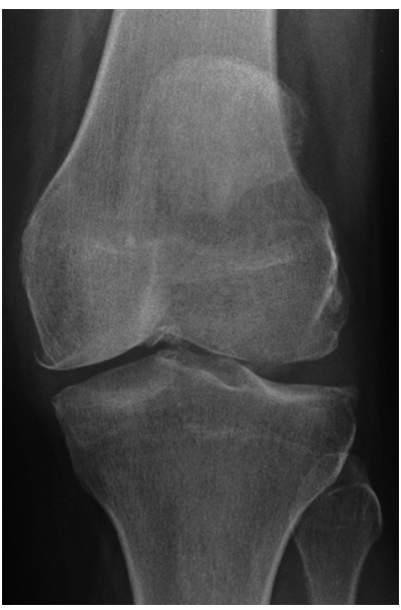

Fig. 1a

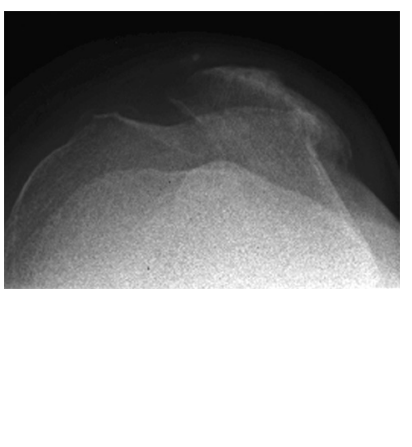

Fig. 1b

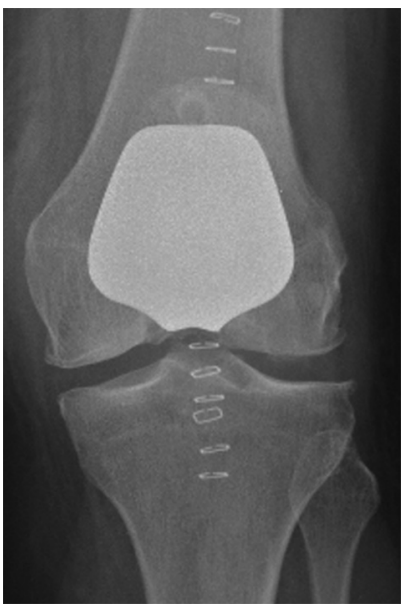

Fig. 1c

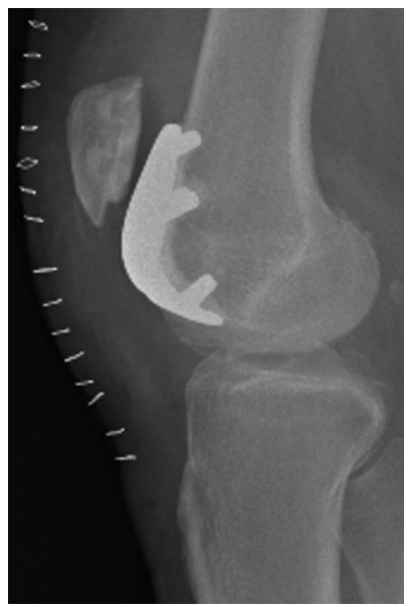

Fig. 1d

Pre-operative a) standing anteroposterior and b) skyline radiographs in a 50-year-old woman with severe patellofemoral degeneration and subluxation. Post-operative radiographs taken on day two show satisfactory placement of the prosthesis on the c) anteroposterior and d) lateral views.

Kooijman, Driessen and van Horn $^{23}$ reported that $24 \%$ of their patients with the Richards II prosthesis underwent further surgery for disease progression at a mean of 15.6 years. In our study only one knee showed evidence of radiological progression of tibiofemoral arthritis, which was asymptomatic, but we accept that our follow-up is short and that further change may yet occur.

The indications for Avon patellofemoral joint replacement are difficult to define. Orthopaedic surgeons have always been aware that the expression of symptoms does not always match the radiological extent of osteoarthritis of various joints, and this is especially true of the patellofemoral joint. ${ }^{24}$ Many elderly patients, after medial unicompartmental knee replacement for anteromedial osteoarthritis, become asymptomatic despite retaining a severely arthritic patellofemoral joint. ${ }^{25}$ It is therefore difficult for a surgeon to adopt a rational approach to isolated replacement of this joint. Our approach has been to select patients who have both isolated bone-on-bone patellofemoral osteoarthritis and severe symptoms (Fig. 1). However, the Avon prosthesis is a tempting solution to the disabling symptoms of younger patients who have either severe trochlear or patellar chondromalacia. Encouraged by our results, we have recently extended the indications to carefully selected patients in this category but remain cautious, as severely disabling symptoms may be out of proportion to the objective pathology.

A further concern about operating on the younger age group is the contact between the patellar component and 
the deep trochlea that occurs beyond $90^{\circ}$ of flexion. At this angle the patella is no longer in contact with the femoral prosthesis, but articulates with the preserved femoral hyaline cartilage. This may cause accelerated wear of the remaining hyaline cartilage, causing symptoms, and eventual abutment of the plastic component on the leading edge of the trochlear prosthesis. Once this occurs, dramatic polyethylene wear is likely to occur. For this reason it is important to recess the trochlear component and achieve a smooth transition between the metal and the currently preserved articular cartilage margin.

In our series, two patients required further surgery. In one, the patella was not resurfaced initially, which resulted in persistent pain, which was relieved by subsequent resurfacing.

One patient, who was dissatisfied with the outcome of surgery, had poor post-operative scores. Her high body mass index $\left(37 \mathrm{~kg} / \mathrm{m}^{2}\right)$ and pre-operative scepticism about patellofemoral replacement may have contributed to this outcome. In addition, she had chronic back pain for which she walked with the aid of crutches because of a tendency to fall. No clinical or radiological abnormality relating to her surgery could be identified. We accept that patient selection may have been poor in this instance.

In conclusion, our results suggest that the Avon patellofemoral joint replacement is a safe and effective means of treating isolated patellofemoral osteoarthritis in carefully selected patients. It may also postpone the need for TKR.

No benefits in any form have been received or will be received from a commercial party related directly or indirectly to the subject of this article.

\section{References}

1. Dalury DF. Total knee replacement for patellofemoral disease. J Knee Surg 2005;18:274-7.

2. Laskin RS, van Steijn M. Total knee replacement for patients with patellofemoral arthritis. Clin Orthop 1999;367:89-95

3. Leadbetter WB. Patellofemoral arthroplasty in the treatment of patellofemoral arthritis: rationale and outcomes in younger patients. Orthop Clin North Am 2008;39:363-80

4. Grelsamer RP, Dejour D, Gould J. The pathophysiology of patellofemoral arthritis. Orthop Clin North Am 2008;39:269-74.
5. Mihalko WM, Boachie-Adjei Y, Spang JT, et al. Controversies and techniques in the surgical management of patellofemoral arthritis. J Bone Joint Surg [Am] 2007;89A:2788-802.

6. Bazina ME, Fox JM, Del Pizzio W, Broukhim B, Ivey FM. Patellofemoral replacement. Clin Orthop 1979;144:98-102.

7. Leadbetter WB, Seyler TM, Ragland PS, Mont MA. Indications, contraindications, and pitfalls of patellofemoral arthroplasty. J Bone Joint Surg [Am] 2006;88A:122-37.

8. Tauro B, Ackroyd CE, Newman JH, Shah NA. The Lubinus patellofemoral athroplasty: a five- to ten-year prospective study. J Bone Joint Surg [Br] 2001;83-B:696701.

9. Ackroyd CE, Newman JH, Evans R, Eldridge JDJ, Joslin CC. The Avon patellofemoral arthroplasty: five-year survivorship and functional results. J Bone Joint Surg [Br] 2007;89-B:310-15

10. Ackroyd CE, Chir B. Development and early results of a new patellofemoral arthroplasty. Clin Orthop 2005;436:7-13.

11. Ahlbäck S. Osteoarthrosis of the knee: a radiographic investigation. Acta Radiol Diagn (Stockh) 1968;Suppl 277:7-22.

12. Dawson J, Fitzpatrick R, Murray D, Carr A. Questionnaire on the perceptions of patients about total knee replacement. J Bone Joint Surg [Br] 1998;80-B:63-9.

13. Insall JN, Dorr LD, Scott RD, Scott WN. Rationale of the knee society clinical rating system. Clin Orthop 1989;248:13-14.

14. Fellar JA, Bartlett RJ, Lang DM. Patellar resurfacing versus retention in total knee arthroplasty. J Bone Joint Surg [Br] 1996;78-B:226-8.

15. Mohammed R, Jimulia T, Durve K, et al. Medium-term results of patellofemoral joint arthroplasty. Acta Orthop Belg 2008;74:472-7.

16. Mont MA, Haas S, Mullick T, Hungerford DS. Total knee arthroplasty for patellofemoral arthritis. J Bone Joint Surg [Am] 2002;84-A:1977-81.

17. Luscombe KL, Lim J, Jones PW, White SH. Minimally invasive Oxford medial unicompartmental knee arthroplasty: a note of caution. Int Orthop 2007;31:321-4.

18. Lim J, Luscombe KL, Jones PW, White SH. The effect of preoperative symptom severity on functional outcome of total knee replacement: patients with the lowest preoperative scores achieve the lowest marks. Knee 2006;13:216-19.

19. Hollinghurst $\mathbf{D}$, Stoney J, Ward $\mathbf{T}$, et al. In vivo sagittal plane kinematics of the Avon patellofemoral arthroplasty. J Arthroplasty 2007;22:117-23.

20. Lonner JH, Jasko JG, Booth RE. Revision of a failed patellofemoral arthroplasty to a total knee arthroplasty. J Bone Joint Surg [Am] 2006;88-A:2337-42.

21. Merchant AC. Early results with a total patellofemoral joint replacement arthroplasty prosthesis. J Arthroplasty 2004;19:829-36.

22. Nicol SG, Loveridge JM, Weale AE, Ackroyd CE, Newman JH. Arthritis progression after patellofemoral joint replacement. Knee 2006;13:290-5

23. Kooijman HJ, Driessen APPM, van Horn JR. Long-term results of patellofemoral arthroplasty: a report of 56 arthroplasties with 17 years of follow-up. J Bone Joint Surg $[B r] 2003 ; 85-B: 836-40$.

24. Han I, Chang CB, Lee S, et al. Correlation of the condition of the patellar articular cartilage and patellofemoral symptoms and function in osteoarthritic patients undergoing total knee arthroplasty. J Bone Joint Surg [Br] 2005;87-B:1081-4.

25. Beard DJ, Pandit H, Ostlere S, et al. Pre-operative clinical and radiological assessment of the patellofemoral joint in unicompartmental knee replacement and its influence on outcome. J Bone Joint Surg [Br] 2007;89-B:1602-7. 